\title{
Psychological Hardiness Predicts Success in US Army Special Forces Candidates
}

\section{Paul T. Bartone*, Robert R. Roland**, James J. Picano*** and Thomas J. Williams**}

\author{
*Center for Technology and National Security Policy, National Defense University, Washington, DC, USA. \\ bartonep@ndu.edu \\ **US Army Physical Fitness Research Institute, US Army War College, Carlisle Barracks, PA, USA \\ ***United States Army Reserve, Joint Exercise Deployment Detachment, Alexandria, VA, USA
}

\begin{abstract}
Military 'Special Forces' represent a high-reliability occupation, where stress levels are often intense and failure can be costly. Selection for such jobs should pay careful attention to psychological factors associated with resiliency under stress. In the present study, US Army Special Forces candidates $(N=1138)$ were assessed for psychological hardiness using a short form of the Dispositional Resilience Scale, and these scores were then applied to predict successful completion of the course. Independent sample $t$-tests and logistic regression analyses confirmed that Special Forces course graduates are significantly higher in psychological hardiness, as compared to non-graduates. Psychological hardiness appears to be an important individual characteristic associated with stress tolerance and successful performance in highly demanding occupations.
\end{abstract}

\section{Introduction}

Secial Forces represent the most elite and demand-

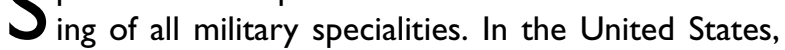
Army Special Forces are expected to function effectively in small autonomous groups, and be able to quickly adapt to changing circumstances, mission demands, and different cultural contexts. Candidates undergo multiple rigorous selection procedures, including a highly stressful 4-week selection and assessment course. On average only $45-55 \%$ of students succeed in this course. Considering that Special Forces are becoming increasingly important for modern military forces, it would be desirable to improve this success rate. Also, understanding the psychological factors that contribute to positive adaptation to highly stressful military selection courses can be applied to improve other selection and training programs. While one study has identified 'motivational' predictors of US Army Special Forces field performance (Kilcullen, Mael, Goodwin, \& Zazanis,
1999), efforts to predict success in selection courses for elite military personnel have thus far met with limited success (Picano, Roland, Rollins, \& Williams, 2002; Picano, Williams, \& Roland, 2006). The present study examines psychological hardiness as a potential predictor of success in the US Army Special Forces assessment and selection course.

Hardiness is a psychological style associated with resilience, good health, and performance under a range of stressful conditions (Bartone, 1999; Kobasa, 1979; Maddi \& Kobasa, 1984). People high in hardiness have a strong sense of commitment to life and work, and are actively engaged in what's going on around them. They believe they can control or influence what happens, and they enjoy new situations and challenges. Also, they are internally motivated and create their own sense of purpose. Conceptually, this is a personality profile well-suited to the Special Forces occupation, which frequently requires its members to operate alone or in small teams, relatively isolated from supporting 
Table 1. Means and standard deviations of hardiness scores (DRS-15) for graduates and non-graduates of US Army Special Forces candidate school (comparable results for the DRS-30 are shown in italics)

\begin{tabular}{|c|c|c|c|c|c|c|}
\hline & $N$ & Mean & $S D$ & $t$ & $p<$ & Cohen's $d$ \\
\hline Graduates & 637 & $\begin{array}{l}34.34 \\
67.53\end{array}$ & $\begin{array}{l}4.1 \\
5.8\end{array}$ & & & \\
\hline Non-graduates & 501 & $\begin{array}{l}33.73 \\
66.09\end{array}$ & $\begin{array}{l}4.5 \\
6.4\end{array}$ & & & \\
\hline Total & 1138 & $\begin{array}{l}34.07 \\
66.90\end{array}$ & $\begin{array}{l}4.3 \\
6.1\end{array}$ & $\begin{array}{l}-2.3 \\
-3.9\end{array}$ & $\begin{array}{l}.02 \\
.001\end{array}$ & $\begin{array}{l}.14 \\
.24\end{array}$ \\
\hline
\end{tabular}

t-test and Cohen's $d$ (effect size) statistics are also displayed. DRS, dispositional resilience scale.

units, and in uncertain environments that will call for spontaneous solutions to unanticipated challenges (Kilcullen et al., 1999).

\section{Description of methods}

A 45-item hardiness measure [the Dispositional Resilience Scale (DRS)] was first reported by Bartone (1989), and was later reduced to 30 - and 15-item versions (Bartone, 1995). The DRS hardiness scale has been used extensively in US military and non-military samples, with excellent results (e.g., Bartone, Ursano, Wright, \& Ingraham, 1989; Britt, Adler, \& Bartone, 2001). In a review of hardiness theory and research, Funk (1992) concludes that both conceptually and psychometrically, the DRS provides the most sound hardiness measure available. Support for the theoretical structure of hardiness was found by Sinclair \& Tetrick (2000) who, using the DRS to hardiness, confirmed a three-factor structure of commitment, control and challenge, nested under a more general hardiness construct.

Both (30- and 15-item) short forms of the DRS hardiness scale have demonstrated good psychometric properties and criterion-related validity across multiple samples (Bartone, 1991, 1995). Cronbach's $\alpha$ reliability coefficients for the 15 -item DRS have been reported at .82 for the total hardiness scale, and for the facets, Commitment $=.77$, Control $=.68$, and Challenge $=.69$ (Bartone, 1999).

For the present study, the sample consists of $N=1138$ candidates from four class cohorts for whom complete hardiness and graduation data were available. The 30-item DRS was used to measure hardiness resilience. The DRS was incorporated into a standard battery of questionnaires completed by all candidates at the start of the course. Candidates are informed that these questionnaires are part of the overall evaluation process, but are not provided further details regarding the specific contents or how results get used. Questions in the battery cover demographic and background information as well as several psychological and mental abilities tests (Picano et al., 2002).
Scores on the short 15 -item DRS version were later calculated and used retrospectively to predict success or failure in the course. Cronbach's $\alpha$ coefficients in this sample are slightly lower than previously reported: .73 for total hardiness, and for the facets, Commitment $=.66$, Control $=.57$, and Challenge $=.68$. Data on graduation or non-graduation from the course were obtained from official records. Hardiness scores of graduates vs nongraduates were compared using independent samples t-tests. In addition, logistic regression analysis was performed to evaluate continuous hardiness scores as a predictor of graduation outcome.

\section{Results}

The sample was all male, because women are currently restricted from Special Forces branches. This group had a mean age of 25.41 years $(S D=3.73)$, with a range of 19-41 years. The overall attrition or failure rate was 44\% $(N=501)$. Graduates did not differ from nongraduates in age. Graduates were significantly higher in their hardiness scores compared with non-graduates. Table 1 displays hardiness mean scores for graduates and non-graduates, as well as for the total group. Scores on the older 30-item DRS measure are presented for comparison purposes. Cohen's $d$ statistic (Cohen, 1988) shows the effect size to be in the smallmedium-small range $(d=.14$ for DRS-15; $d=.24$ for DRS-30). As a further check, logistic regression confirmed hardiness is a significant predictor of success in the course (graduation) $(p<.02)$. The obtained oddsratio of 1.033 indicates that for each 1 -point increase in hardiness scores, the probability of graduating rises by approximately $3.3 \%$.

\section{Discussion}

This study found that psychological hardiness makes a small but significant contribution to successful completion of a rigorous Army Special Forces candidate school. Previous efforts to identify psychological factors that predict success in similar elite military courses have 
met with little success. For example, Picano et al. (2002) report that out of 80 personality and intelligence measures examined, only two (the NEO-Big Five facets of E4-activity and A2-straightforwardness) discriminated graduates from non-graduates. And when entered into a logistic regression with a sentence completion test (SCT) of defensiveness, these Big Five facets were non-significant and only SCT defensiveness discriminated between the two groups. In a study focused on US Navy Special Forces, McDonald, Norton, and Hodgdon (1990) found successful candidates were more social, more emotionally stable, and more likeable. However, Hartmann, Sunde, Kristensen, and Martinussen (2003) in their assessment of Norwegian Naval Special Forces candidates, found that while emotional stability helped predict success, scoring higher on extraversion was negatively related to success.

Thus, psychological hardiness may offer a more global and positive personality factor to help predict success in Special Forces candidate school. The relation of hardiness to performance is even more significant considering a likely restricted range problem. All candidates, whether successful or not, tend to score higher in hardiness than other military and non-military groups (Bartone, 1991). In addition, demand characteristics of the selection situation (Picano et al., 2002) could also possibly lead to inflated hardiness scores, making it even more difficult to detect real effects. The significant observed effects of hardiness on success in the course are thus all the more noteworthy considering these potential restricted range and demand characteristic influences on hardiness scores.

\section{Conclusion}

The Army Special Forces is a "high reliability occupation,' one in which demands are high and failure can be catastrophic (Flin, 2001; Picano et al., 2006). The best knowledge available should be applied to selection of personnel for such occupations. This study has found that individuals who successfully complete a rigorous Army Special Forces candidate school are significantly higher in personality hardiness than those who fail. Effects are modest, but offer a significant and noteworthy contribution to the growing evidence for positive personality factors that predict success in extreme environments. Considering both theory and empirical findings on hardiness as a personal stress-resiliency resource (Ouellette, 1993), it makes sense that hardiness is associated with successful performance under the stressful conditions of Special Forces candidate school. The identification of psychological characteristics such as hardiness that predict success in high demand assessment and selection programs may also help in the design of training approaches to increase soldier resilience in the face of sustained stressors. Additional research should examine hardiness as a potentially valuable personality style in Special Forces as well as other highly demanding occupations. Despite a variety of obstacles to the use of psychological variables in selection (Flin, 2001), evidence increasingly supports the use of personality variables such as hardiness along with other variables in the selection process for highly demanding jobs.

\section{References}

Bartone, P.T. (1989) Predictors of Stress-Related Illness in City Bus Drivers. Journal of Occupational Medicine, 3, 657-663.

Bartone, P.T. (1991) Development and Validation of a Short Hardiness Measure. Paper Presented at the American Psychological Society Annual Convention, Washington, DC.

Bartone, P.T. (1995) A Short Hardiness Scale. Paper Presented at the American Psychological Society Annual Convention, New York.

Bartone, P.T. (1999) Hardiness Protects Against War-Related Stress in Army Reserve Forces. Consulting Psychology Journal, 51, 72-82.

Bartone, P.T., Ursano, R.J., Wright, K.W. and Ingraham, L.H. (1989) The Impact of a Military Air Disaster on the Health of Assistance Workers: A prospective study. Journal of Nervous and Mental Disease, 177, 317-328.

Britt, T.W., Adler, A.B. and Bartone, P.T. (2001) Deriving Benefits from Stressful Events: The role of engagement in meaningful work and hardiness. Journal of Occupational Health Psychology, 6, 53-63.

Cohen, J. (1988) Statistical Power Analysis For The Behavioral Sciences (2nd edn). Hillsdale, NJ: Lawrence Earlbaum Associates.

Flin, R. (2001) Selecting the Right Stuff: Personality and highreliability occupations. In: Roberts, R.W. and Hogan, R. (eds), Personality Psychology in the Workplace. Washington, DC: American Psychological Association, PP. 253-276.

Funk, S.C. (1992) Hardiness: A review of theory and research. Health Psychology, 11, 335-345.

Hartmann, E., Sunde, T., Kristensen, W. and Martinussen, M. (2003) Psychological Measures as Predictors of Training Performance. Journal of Personality Assessment, 80, 87-98.

Kilcullen, R.N., Mael, F.A., Goodwin, G.F. and Zazanis, M.M. (1999) Predicting U.S. Army Special Forces Field Performance. Human Performance in Extreme Environments, 4, 53-63.

Kobasa, S.C. (1979) Stressful Life Events, Personality, and Health: An inquiry into hardiness. Journal of Personality and Social Psychology, 37, 1-11.

Maddi, S.R. and Kobasa, S.C. (1984) The Hardy Executive. Homewood, IL: Dow Jones-Irwin.

McDonald, D.G., Norton, J.P. and Hodgdon, J.A. (1990) Training Success in U.S. Navy Special Forces. Aviation, Space, and Environmental Medicine, 61, 548-554.

Ouellette, S.C. (1993) Inquiries into Hardiness. In: Goldberger, L. and Breznitz, S. (eds), Handbook of Stress: Theoretical and clinical aspects (2nd edn). New York: The Free Press, pp. 77-100. 
Picano, J.J., Roland, R.R., Rollins, K.D. and Williams, T.J. (2002) Development and Validation of a Sentence Completion Test Measure of Defensive Responding in Military Personnel Assessed for Nonroutine Missions. Military Psychology, 14, 279-298.

Picano, J.J., Williams, T.J. and Roland, R.R. (2006) Assessment and Selection of High-Risk Operational Personnel. In:
Kennedy, C.H. and Zillmer, E.A. (eds), Military Psychology: Clinical and operational applications. New York: Guilford, Pp. 353-370.

Sinclair, R.R. and Tetrick, L.E. (2000) Implications of Item Wording for Hardiness Structure, Relation with Neuroticism, and Stress Buffering. Journal of Research in Personality, 34, 1-25. 